\title{
Some Experiments on the Influence of Temperature on the Rate of Growth in Pisum sativum.
}

BY

\section{LEITCH, B.Sc.}

\section{With Plate I and ten Figures in the Text.}

$T$ HE first work of importance on the subject of the relation of temperature to growth-processes in higher plants is that of Sachs ('60), on the effect of temperature on germination. His method is to compare the amounts of growth in a given time at different temperatures. The time is measured from the end of the soaking, and in Pisum the time-interval chosen is forty-eight hours. For Pisum he concludes that the temperature at which germination proceeds most quickly is below $22^{\circ}$. This method seems to be defective, since the amount of growth of the roots in the rather long period of forty-eight hours will be much affected by the ease or difficulty with which the root bursts the seed-coat, there being great differences in this respect between peas treated in exactly the same manner and giving the same growth-curve afterwards.

Köppen ('70) finds that alterations of temperature exercise a retarding influence on growth, and makes a number of determinations of the rates of growth at temperatures, for Pisum, from $10^{\circ}$ to $40^{\circ}$. These values show a great inconstancy, and besides, in view of the experimentation-time of forty-eight hours and the method employed, their value is small.

Petersen ('74) points out the obvious defects of Köppen's work, demonstrates that variations in temperature, as such, have no effect upon growth, and that the curve of growth at non-injurious temperatures must be a curve convex to the temperature-axis.

Sachs ('87) investigates the occurrence of the Grand Period in different seedlings, and finds it to occur in Pisum on the ninth or tenth day. It is to be noted that in his experiments on the fifth to sixth day, the temperature varies between $10^{\circ}$ and $19.8^{\circ}$, a variation sufficient to disturb the result considerably. He gives figures for the relation of growth to temperature in Zea Mais, and quotes a judicious selection from Köppen's figures showing a relation agreeing in type with his own determinations.

[Annals of Botany, Vol. XXX. No. CXVII. January, 1916.] 
Askenasy ('90) finds for Zea Mais that the Grand Period curve is very flat; the maximum rate of growth is reached when the roots are 30 to $40 \mathrm{~mm}$. long, and the rate remains constant till the appearance of the sideroots when the main roots are about $\mathrm{I} 30 \mathrm{~mm}$. long. He finds also, that in roots grown at a high temperature and suddenly subjected to a temperature of $3^{\circ}$ to $6^{\circ}$ the growth is suddenly stopped (contraction usually occurs), and that, on the return of the roots to the initial temperature, the rate is depressed below the normal rate, for a time depending on the lowness of the intermediate temperature, and the length of their subjection to it.

True ('95) confirms these latter experiments of Askenasy, using Vicia Faba, Lupinus albus, and Pisum sativum, and finds further that a sudden change from a low to a high temperature is, if the interval be great enough (from $3^{\circ}$ to $18^{\circ}$ ), followed by a sudden elongation of the root, with a subsequent period of depressed growth. His experiments with Vicia Faba on the effect of transitions between $18^{\circ}$ and $30^{\circ}$ are of very doubtful value, since $30^{\circ}$ is, for Vicia, 'above the optimum'.

More recently Schmidt ('13) has demonstrated for Humulus Lupulus the very close dependence of growth, under ordinary open-air conditions, upon temperature. His growth and temperature curves vary, in all cases, in the same manner, and often (cf. No. I 7 ) almost exactly proportionally.

Finally, Vogt (cited in Jost, '13) gives a series of determinations, but here nothing is told of the method of experimentation, and the experimentation-time is again 24 hours, a time, as will appear later, much too long, at least for high temperatures.

The experiments to be described are on Pisum sativum, the material belonging to one sample, carefully mixed at the beginning; and they are in two parts. The first part consists of experiments with the long experimentation-time of $22 \frac{1}{2}$ hours. Their purpose was, first, to map out the field, and second, by the use of much larger numbers than is possible in more accurate microscopic work, to afford an idea of the amount of variation in the material. In the second part, the experimentation-time is short, and the determinations made by microscope measurements.

\section{First Series.}

The time occupied daily in preparing material and making measurements in the first series of experiments being about one and a half hours, the experimentation-time became conveniently $22 \frac{1}{2}$ hours. At first (the experiments were begun in December), the peas were soaked and germinated at room temperature, about $15^{\circ} \mathrm{C}$. during the day. But soon it was found that the temperature fell too low during the night to give a suitable length of root on the third day, and from then onwards the soaking and germination took place in an electric thermostat whose temperature varied slowly between $15^{\circ}$ and $17^{\circ} \mathrm{C}$. The peas germinated in an apparatus first 
constructed by Professor Johannsen and not as yet described. A photograph of it appears in Plate I, Fig. I, and the apparatus is made in the following manner: A dish of suitable size is chosen and fitted in the foot with a plate of cork. The whole is lined with paraffin, and pieces of wire, or needles, are stuck in the cork in pairs, at such distances that two rubber tubes, which are placed round them, press closely together. The dish is filled with plaster of Paris, and when it has set the rubber tubes are pulled out, the form removed, and the apparatus is ready. A lid as shown in the photograph is quite simply made with a similar lined dish and a smaller plate of cork, covered with paraffin, to press into the soft plaster of Paris. Convenient sizes for the germination of peas are: whole apparatus, I0 $\times 15 \mathrm{~cm}$., and rubber tubes 0.7 and $0.5 \mathrm{~cm}$. in diameter, $0.6 \mathrm{~cm}$. apart.

For use the apparatus is thoroughly moistened and is set in a dish containing a little water. In the experiments proper, as distinct from the first

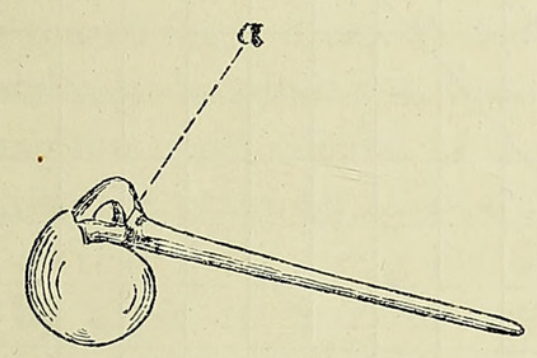

TEXT-FIG. I.

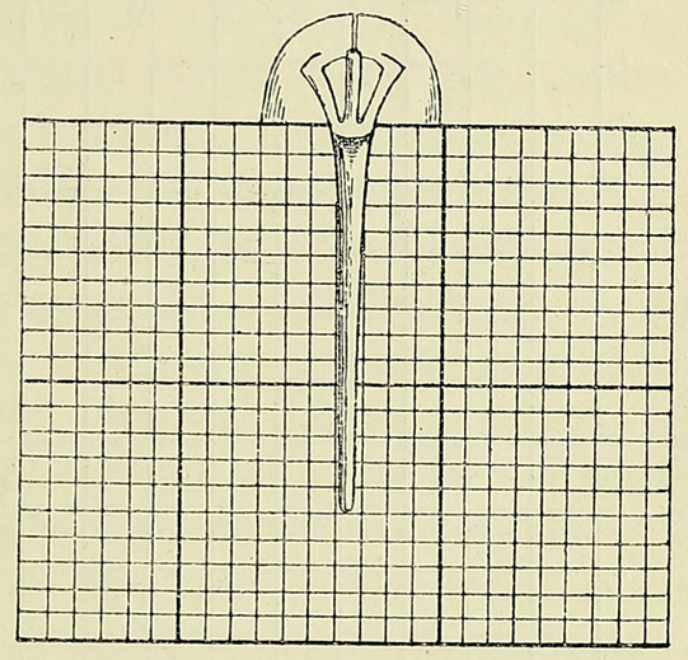

TEXT-FIG. 2.

two days' growth, instead of the porous plaster-of-Paris lid, a bell-jar lined with filter-paper was used to cover the peas, and a petri dish with $\mathrm{NaOH}$ was placed above the peas to prevent the accumulation of $\mathrm{CO}_{2}$.

The peas were soaked for $22 \frac{1}{2}$ hours, and then placed seventy altogether, each day, on this apparatus and left for $46 \frac{1}{2}$ hours. At the beginning of the third day after soaking, therefore, the thirty-five most uniform in length were selected and measured. The method of measurement was as follows: the triangular piece of the seed-coat burst up in germination was removed, and a piece of millimetre-paper placed behind the root so that a centimetre line came exactly behind the point marked $a$ in Text-fig. I. The length of the root was read off in millimetres, so that Professor Johannsen's method of measuring ' up to' was used; that is, the next higher millimetre was always taken as the reading. In Textfig. 2, which shows the paper in place, the length is $15 \mathrm{~mm}$., but, if the 
root-tip had been between the $\mathrm{I}_{4}$ and $\mathrm{I} 5 \mathrm{~mm}$. lines, it would also be called I $5 \mathrm{~mm}$.

The experiments were carried out in a gas thermostat, where it was possible to vary the temperature from $\mathrm{II}^{\circ}$ upwards. The temperature was recorded by thermograph tracings, and even at the highest temperatures used the fluctuations shown did not exceed $0.5^{\circ}$. Temperatures below II $^{\circ}$ were obtained according to the weather in a room of very constant temperature, where a thermograph tracing was a straight line for days if the windows were undisturbed and the door kept closed. Temperatures near to and below zero were obtained in the open air. The lowest was in an experiment where the temperature did not rise above $-2^{\circ}$ and where the minimum

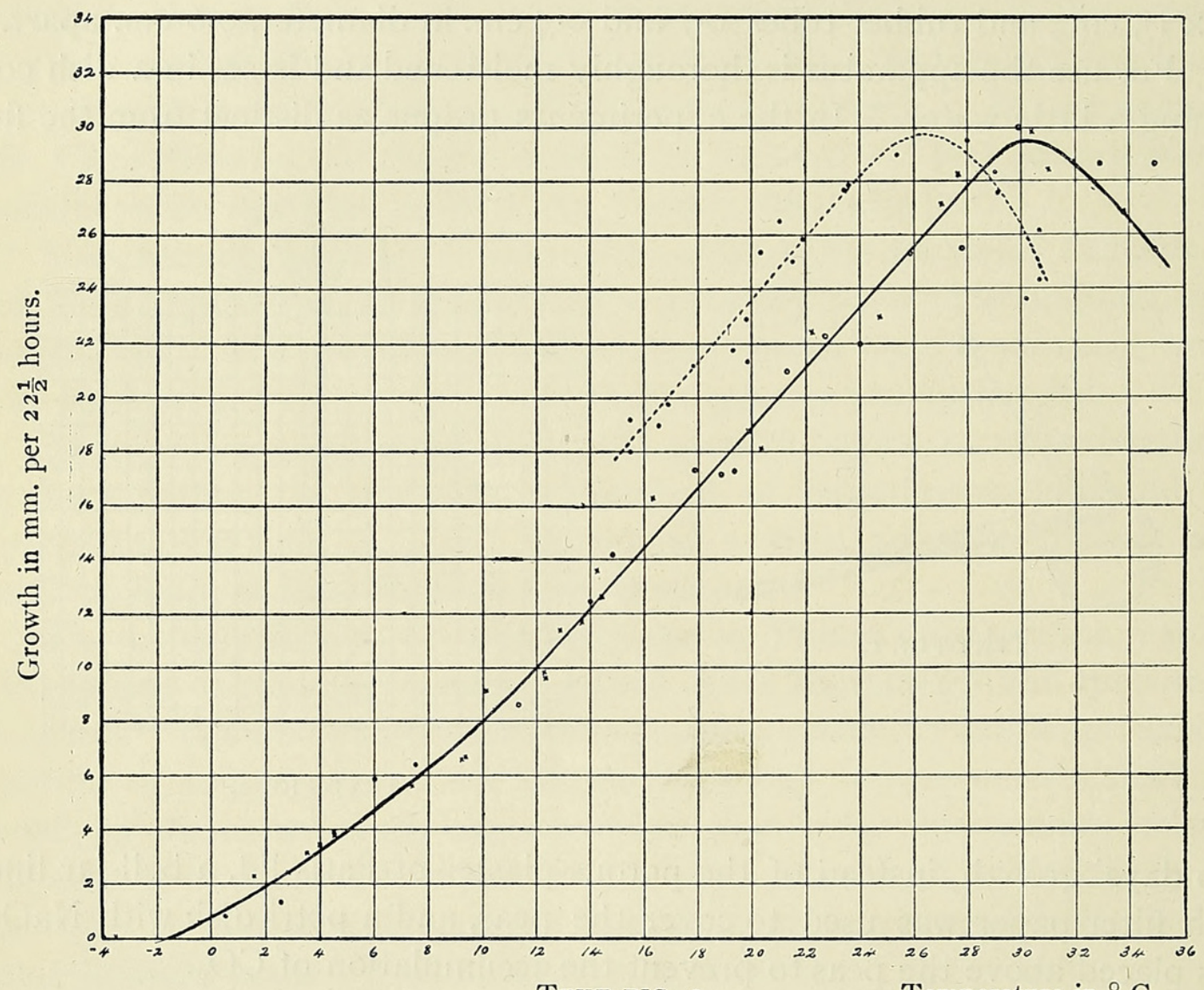

TeXT-Fig. 3 .

Temperature in ${ }^{\circ} \mathrm{C}$.

was $-5^{\circ}$. Here no growth took place; instead, a slight general contraction. The roots were frozen, but, on thawing at room temperature, continued to grow.

It was intended that the experiments should be in two series; the first was completed, and in the second-which began about $15^{\circ}$-for some cause which I have been quite unable to explain, the values of the growth-rate suddenly rose and maintained a level uniformly above those of the first series to $28^{\circ}$, after which the usual fall of the rate took place, that is to say, at a temperature which is about two degrees lower than in the first series. At this point, in view of these results, the number of peas soaked each day 
was reduced to the minimum possible. About ninety were required, since about 20 per cent. are injured or deformed or of extremely large or small size. It was thus hoped to eliminate unconscious selection of the soaked peas. From then onwards, too, the germinating apparatus and all dishes used were periodically sterilized as a precautionary measure. Under these conditions a third series was carried out, and it agreed exactly with the first.

Detailed figures are given in Table I, and the results are plotted in Text-fig. 3. Table'I shows the average initial length, average growth in $22 \frac{1}{2}$ hours, together with the standard deviation and probable error of the mean for each experiment. The experiments are arranged in chronological order.

\section{Second Series.}

In the second part, the peas were grown in the following way. They were soaked and germinated as before in the electric thermostat, but remained in the plaster-of-Paris apparatus for only one day, at the end of which the roots were about 5 to $10 \mathrm{~mm}$. long. Then they were placed in tubes measuring $\mathrm{I} .8 \mathrm{~cm}$. in diameter and $10 \mathrm{~cm}$. in height, with corks bored eccentrically to admit the thermometer during the experiment, and having a triangular piece cut out at one side so that the air in the tube was in contact with the outer air at all times. In the cork a capillary glass tube was fixed so that it lay along the side of the tube, and the pea was fixed to the cork by a pin so that the root was in contact with the side of the tube, between it and a slip of filter-paper and just beside the capillary tube. The filter-paper dipped in water. The root was thus supplied with sufficient moisture at all temperatures and air had free access to it. It was found that without the capillary tube the filter-paper adhered to the glass, and the resistance thus offered to the growth of the root was sufficient to cause curvatures. Plate I, Fig. 2, is a photograph of peas so grown. By this method a large proportion of the peas grew diagrammatically straight, and only a small proportion were incapable of accurate measurement. A slight curvature, such as that shown in the tube to the right in the photograph, is of no significance, since the experimentation-time is so short that the inclination does not appreciably change. In these cases, readings are taken with the eye-piece slightly rotated so that the micrometer scale is perpendicular to the axis of the root.

With the magnification used, a reading $I$ on the micrometer scale represented $0.056 \mathrm{~mm}$.

A beaker served as a water-bath, and the temperature was regulated by a micro-burner and Roux's regulator. Except at low temperatures, the temperature of the water remained constant to within $0.5^{\circ}$. For temperatures below $15^{\circ}$ a slow current of water flowed through the beaker ; a conical 
flask was interposed between the beaker and the tap, and for temperatures between that of the water and $15^{\circ}$ the micro-burner was used to heat the flask. Between $I^{\circ}$ and $5^{\circ}$ ice was used. By these means a complete range of temperatures from $\mathrm{I}^{\circ}$ upwards was available.

The experiments from $15^{\circ}$ upwards were performed on a table built into the ground and therefore free from any danger of disturbance by vibration or shaking. At lower temperatures they were carried out in a colder room where such an arrangement was not available, but the room was a basement one, and repeated tests showed no disturbance by shaking.

In view of the great amount of trouble to be saved by conducting the microscope experiments in daylight, a series of experiments was made to test for a possible influence of a sudden transition from dark to light, or as Vogt ('14) incidentally records for Lupinus, in his paper on the influence of light on growth in Avena, for a possible increase of the rate of growth in light. The temperature of about $25^{\circ}$ was chosen for these experiments as giving a high rate of growth likely to show reactions clearly, and as being subject to no injurious effect.

Table $\mathrm{A}$ gives the results of these experiments; the readings are half-hour readings, and the numbers micrometer divisions. In Experiments 3, 7, and 9, a 100-C.P. electric lamp at about fourteen inches was used in addition to daylight.

\section{TABLE A.}

$\downarrow$ Commencement of light. $\uparrow$ Stoppage of light.

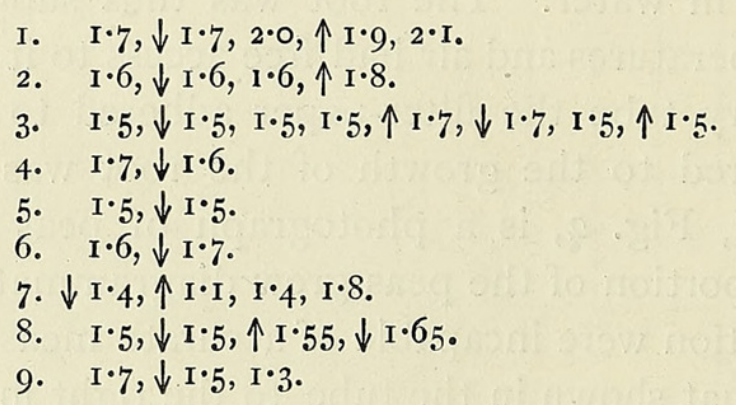

The means are, in dark, $\mathbf{I} \cdot 6$; in light, $\mathbf{I} \cdot 55$. These readings show that, neglecting for the moment Experiments 3, 7, and 9, the fluctuations in the readings show no constant relation to the presence or absence of light. The fluctuation is, indeed, such as takes place in experiments under uniform conditions. (Compare Experiments 3 and 4 on change of temperature, quoted below.) Experiment 9 shows a fall in light, and Experiment 7 a rise in darkness after illumination-which results do not necessarily confirm each other-and Experiment 3 under the same conditions shows, as the experiments in daylight alone do, no influence of the light. 
To illustrate the absence of any 'stimulatory' effect, Experiment 2 may be cited in full.

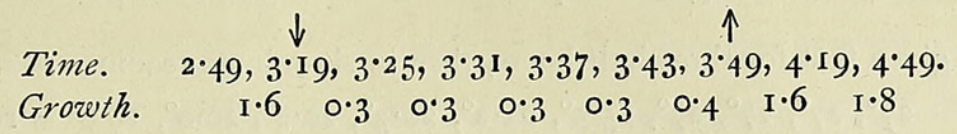

The fifth reading in light is due to the inaccuracy in reading, readings being ' up to' one micrometer division $(0.056 \mathrm{~mm}$.), and the rise to $\mathrm{I} .8 \mathrm{in}$ the last half-hour is a difference such as occurs as a normal fluctuation under uniform conditions.

Two of the experiments to be described later, on the Grand Period of growth, were also performed in darkness for comparison, and they showed no difference from those in light. The shoot was etiolated, but the rate of growth of the root was unaffected. Therefore, at least within the conditions under which all the rest of the experiments took place, light exerts no influence on the rate of growth.

In the next place there is to be considered the effect of a sudden rise or fall of temperature. In all experiments the same results were found, namely that the roots assumed immediately on reaching the new temperature the rate of growth characteristic for it, and that, for temperatures up to $29^{\circ}$, such fluctuations as take place afterwards occur without showing either a typical time or mode of occurrence, so that, taking the mean of a number of peas, the rate of growth, for at least six hours, is represented by a straight line. To illustrate this the following experiments are quoted:

\section{Fall to low temperature from thermostat temperature.}

Date.

March 7 .

March 8.

2.

$\begin{array}{ll}\text { March 7. } & 3.30 \text { p.m. to } 4 \text { p.m. } \\ & 4 \text { p.m. to } 4.30 \text { p.m. } \\ \text { March 8. } & 4.30 \text { p.m. to } 5 \text { p.m. } \\ & 5 \text { p.m. to Io.2 } 7 \text { a.m. } \\ & \text { Io.40 a.m. to I I.IO a.m. } \\ & \text { II.Io a.m. to I I.40 a.m. }\end{array}$

Time.

2.27 p.m. to 2.57 p.m.

2.57 p.m. to 3.27 p.m.

II.42 a.m. to I 2.12 p.m.

I $2 . \mathrm{I} 2$ p.m. to I $2.4^{2}$ p.m.

I $2.4^{2}$ p.m. to I.I 2 p.m.
II. IO a.m. to II.40 a.m.

Growth.
O.I
$O \cdot I$
$O \cdot I$
$O \cdot I$
$O \cdot I$

$\begin{array}{ll}0.1 & 4.9^{\circ} \\ 0.2 & 4.9^{\circ} \\ 0.2 & 4.9^{\circ} \\ 0.1 \text { I (mean) } & 3.5^{\circ} \\ 0.1 & 3.8^{\circ} \\ 0.2 & 3.9^{\circ}\end{array}$

The fall here is from thermostat temperature, $15^{\circ}$ to $I 7^{\circ}$, to about $4^{\circ}$. In both, the characteristic low rate of growth is assumed at once and maintained. In No. 2, where the growth during the night was measured, giving a mean rate of $0 . I \mathrm{I}$, a fall is seen as compared with the rate from 3.30 to 5 , which is 0.17 , due to the fall of temperature from $4.9^{\circ}$ to $3.5^{\circ}$ during the night. In No. I the rate on the 8 th is the same as on the previous day, it being measured at nearly the same temperature. 


\section{Fall from high temperature to room temperature.}

Rate of growth given first for three half-hours, then in six-minute readings :

Temperature. $\quad 27^{\circ}, 27^{\circ}, 27^{\circ}, 27^{\circ}, 25 \cdot 5^{\circ}, 21 \cdot 2^{\circ}, 20 \cdot 3^{\circ}, 20 \cdot 2^{\circ}, 20 \cdot 0^{\circ}, 19 \cdot 8^{\circ}=$ room temperature. $\begin{array}{lllllllll}\text { Rate of growth. } \quad I .8 & \mathrm{I} \cdot 8 & 2.1 & 0.2 & 0.2 & 0.3 & 0.2 & 0.2\end{array}$

\section{Rise of temperature.}

Rate of growth given during first half-hour in six-minute readings, then in half-hour readings :

Temperature. Rate of growth.

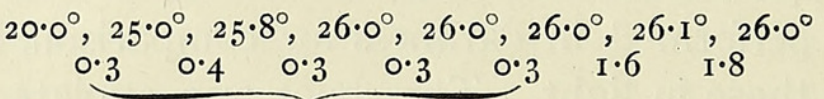

Temperature. Rate of growth.

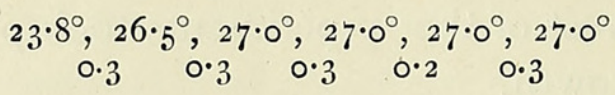

6.

Temperature. ${ }^{2} \quad 23 \cdot 9^{\circ}, 26 \cdot \mathrm{I}^{\circ}, 26 \cdot 5^{\circ}, 26 \cdot 6^{\circ}, 26 \cdot 6^{\circ}, 26 \cdot 6^{\circ}$

$\begin{array}{llllll}\text { Rate of growth. } \quad 0.4 & 0.3 & 0.3 & 0.4 & 0.3\end{array}$

7. Finally the following experiment, where the results given are the means of measurements of eight peas: the rise of temperature is from room-temperature, about $18^{\circ}$ to $25^{\circ} 2^{\circ}$.

In the first, second, and third interval of ten minutes, the mean rate of growth was: $0.50,0.475,0.475$; that is, practically identical; and the rates in the first and sixth half-hours were $\mathrm{I} \cdot 45$ and $\mathrm{I} \cdot 45$.

From these experiments it will be clear that a change of temperature is, in itself, without effect; but that the rate of growth follows immediately and accurately any considerable change of temperature.

The next point to be considered is the possible effect on the experiments of the Grand Period of growth of the roots. In view of Sachs's determinations, it appeared at first as if, in my experiments, taking place always at the beginning of the third day of growth, the slight rise to be expected during that day would be negligible, at least in short-period experiments. But in the long-period experiments at higher temperatures it had already become probable to me that Sachs's results did not apply, and therefore, at the beginning of the microscope experiments, a series of determinations on the time of occurrence of the Grand Period was begun and continued intermittently. The roots were grown in long test-tubes with exactly the same other arrangements as in the microscope experiments, and measurements were made by applying a millimetre scale to the outside of the tube, a method which avoids all disturbances of growth by handling. Table II gives a full account of the results. Measurements were never continued after the appearance of the side-roots. 
The conclusions from Table II are (I) that the roots germinated and grown at a constant temperature (Expts. 9, IO, II) show the Grand Period on the third day at $14^{\circ} \mathrm{C}$, and on the second day at $23^{\circ} \mathrm{C}$. ; (2) that roots germinated and grown for one day at a temperature of $15^{\circ}$ to $17^{\circ} \mathrm{C}$. and then transferred to a different constant temperature show the Grand Period also on the third day, but if they be transferred to a different higher temperature at the beginning of the second day, the Grand Period occurs on the second day. Thereafter, in all cases, the rate falls slowly to the time of appearance of the side-roots; (3) that the side-roots appear at a definite length of the main root-in all cases except one, when the main root is between 80 and $90 \mathrm{~mm}$. long. They therefore appear earlier, in time, at high temperatures than at low. This agrees with Askenasy's results so far as the appearance of the side-roots at a particular length of the main root is concerned, but he found that the rate of growth of the main root maintained a constant value from the beginning of the Grand Period till then.

Text-figs. 4 and 5 show the results of Expts. 9 and Io respectively.

With regard to the bearing of these facts on the experiments in general,

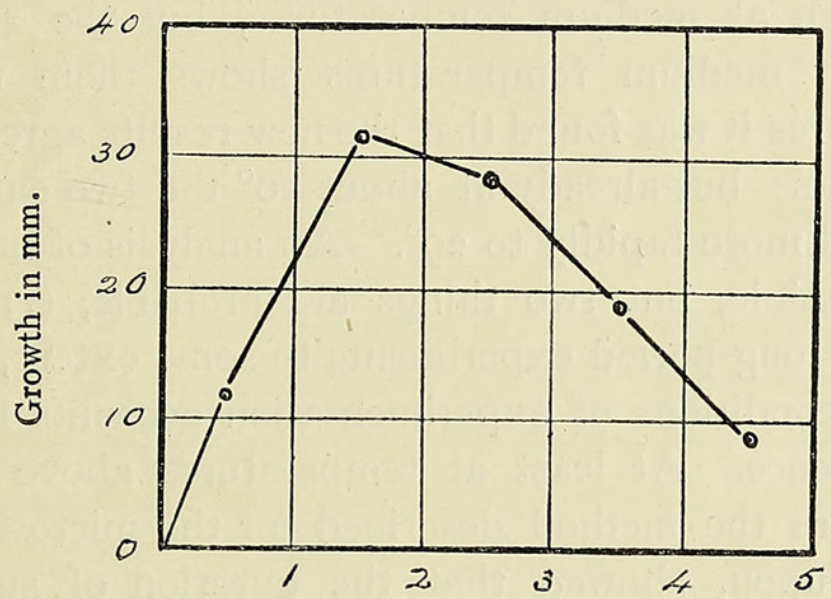

Text-Fig. 4 .

Days.

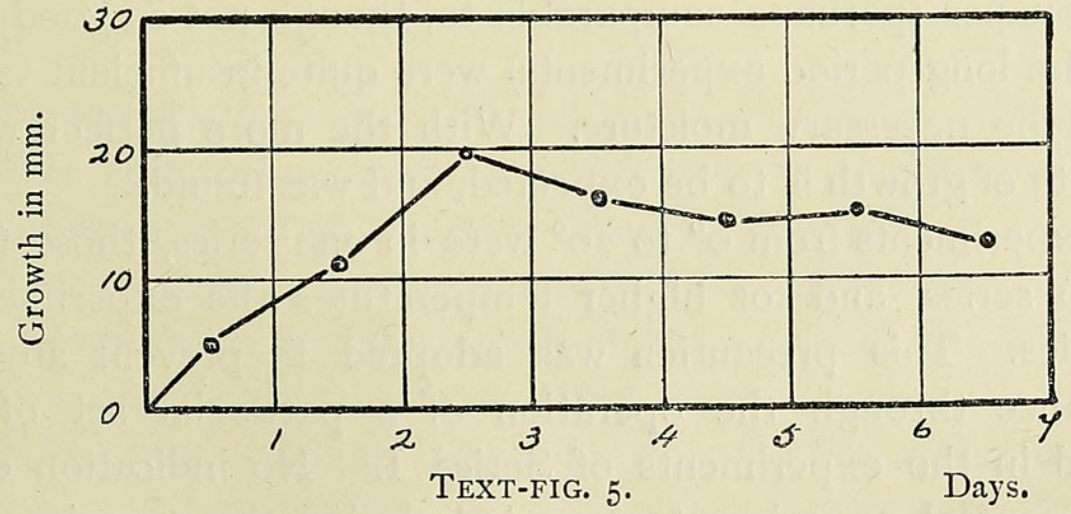

all measurements, being made at the beginning of the third day of growth, are made in that phase where the rate of growth is, as nearly as possible, at its highest value and most constant. Further, as has already been deter- 
mined, the rate of growth, under the conditions of experimentation, is actually constant during the whole of the third day at very low temperatures and at $25^{\circ}$ for at least six hours. Since, therefore, all points on the curve of growth are means of readings taken over usually three half-hours (sometimes one or two; never more than six), it may be taken that the difference between readings at different temperatures is entirely due to the difference between the temperatures. On the other hand, in the long-period experiments there will probably be a slight disturbance due to the passing of the Grand Period during the time of the experiment.

At the commencement of the microscope experiments, I decided that most time should be devoted to low temperatures and to high, because, on the one hand, I thought that there might be a possible inaccuracy in the long-period determinations at low temperatures due to the length of time necessary for the apparatus to sink from the temperature of the laboratory, at which measurements were made, to the temperature of the experimentation room or the open air; and, on the other hand, the long-period method is impossible as a means of accurate analysis at high temperatures. The number of experiments at low and at high temperatures is therefore much greater than at medium temperatures, but the agreement of the determinations at medium temperatures shows them to be sufficient. At low temperatures it was found that the new results agreed with the longperiod experiments : but already at about $10^{\circ}$ the two curves diverge, and separate more and more rapidly to $29^{\circ}$. An analysis of the reasons for this has not been possible, but two things are probable, (I) that the Grand Period affects the long-period experiments to some extent, and (2) that the difference in the conditions of experimentation accounts for a considerable part of the difference. At least at temperatures above $20^{\circ}$, preliminary experiments, before the method described for the microscope experiments was determined upon, showed that the question of sufficient moisture is of the greatest importance, and that devices such as lining the tube with moist filter-paper (perhaps comparable to, though not so good as, the conditions in the long-period experiments) were quite insufficient to supply the roots with the necessary moisture. With the more perfect water-supply a higher rate of growth is to be expected, and was found.

The experiments from $0^{\circ}$ to $20^{\circ}$ were in one series, those from $20^{\circ}$ to $28^{\circ}$ in two series, and for higher temperatures the experiments were in several series. This precaution was adopted to prevent any possibility of disturbance through the operation of a particular set of conditions, as occurred in the experiments of Series I. No indication of any such appeared; control experiments, repeated during the experiments at high temperatures to make sure of the good condition of the roots, always gave results agreeing exactly. The experiment at $25^{\circ}$ quoted in connexion with the question of 'temporary stimulation' by a rise of temperature (Expt. 
No. 7) was the last experiment done, and it shows conclusively that no alteration or disturbance in the material had occurred, for the value it gives lies exactly on the growth-rate temperature curve. Table III gives the results from $0^{\circ}$ to $29^{\circ}$, and Text-fig. 6 shows the relation of growth to temperature in graphical form. Up to and including $28^{\circ}$, the growth-rate is constant during the time of the experiment.

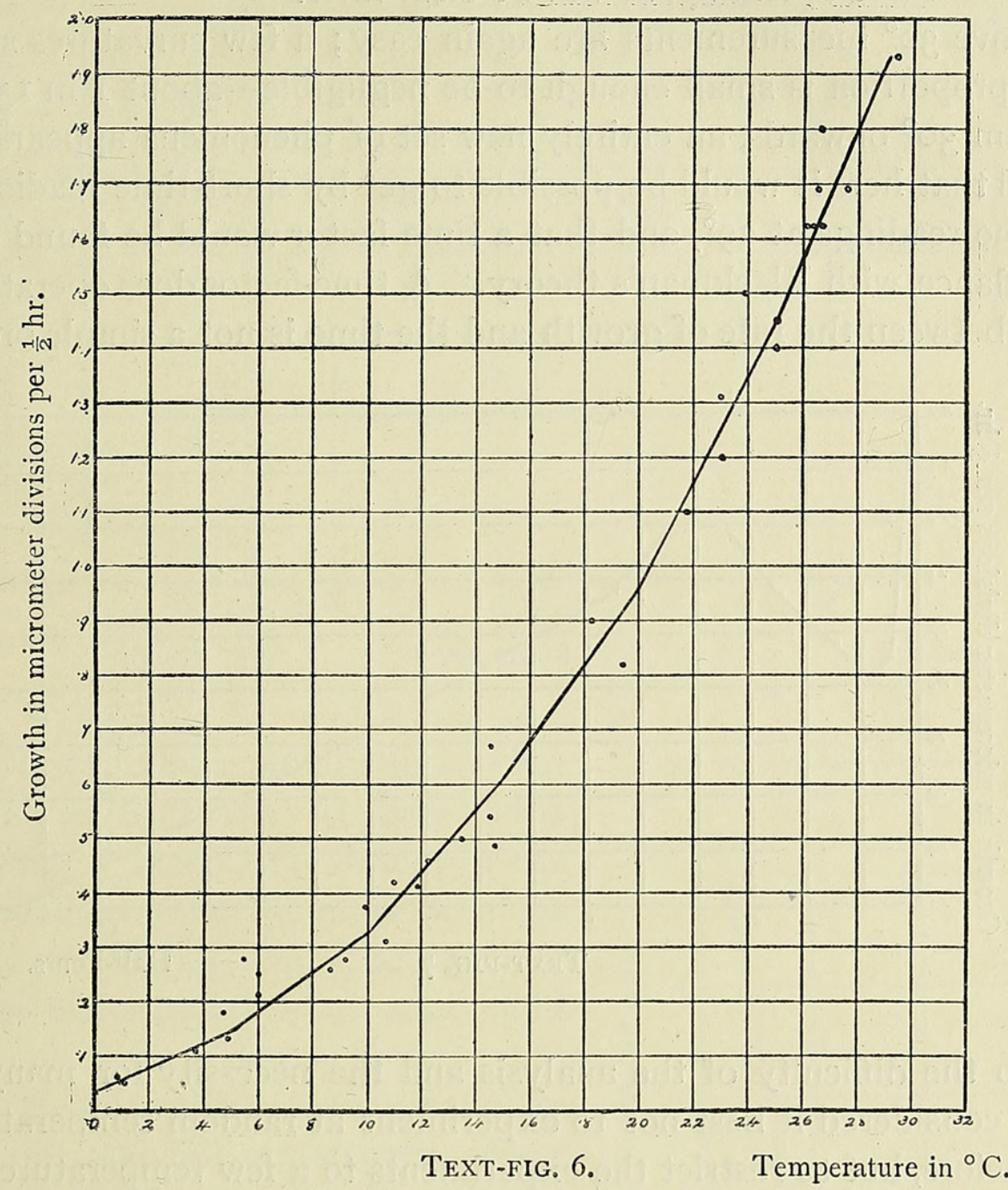

At temperatures between $28^{\circ}$ and $30^{\circ}$ a new factor comes into operation. At this point, experimentation becomes very difficult. On raising the temperature to about $29^{\circ}$, in most cases rapid and sharp curvatures took place. These curvatures are not the gentle curvatures already referred to, extending over perhaps half the length of the root and altering in direction so little and so slowly as to have no effect on the accuracy of the measurements. These occur over only about $5 \mathrm{~mm}$. at the tip of the root and result in a sharp inward bend of the tip, which makes measurement impossible. More than one in two of the roots used curved in this way so that they could not be measured at all, and of the others, most could be measured only for two half-hours. Any number of measurements, however great at 
this temperature, would therefore be an analysis of less than half the material. Indeed, this fact, together with the fact that above $30^{\circ}$ a few similar curvatures still take place, shows that this point is a critical point at which, even if measurements in numbers were easy, an accurate analysis would be made very difficult, if not impossible, by the necessity for referring each individual to one or other of two types, according to whether a timefactor is or is not operating, as will be clear later.

Above $30^{\circ}$ measurements are again easy; a few curvatures still occur, but the proportion is small enough to be negligible-about I in I 5 .

From $30^{\circ}$ onwards, an entirely new set of phenomena appears. I had expected that here it would be possible to get by short-time readings values above the readings at $29^{\circ}$, and that a time-factor would be found operating in accordance with Blackman's theory. A time-factor does operate, but the relation between the rate of growth and the time is not a simple one. Here,

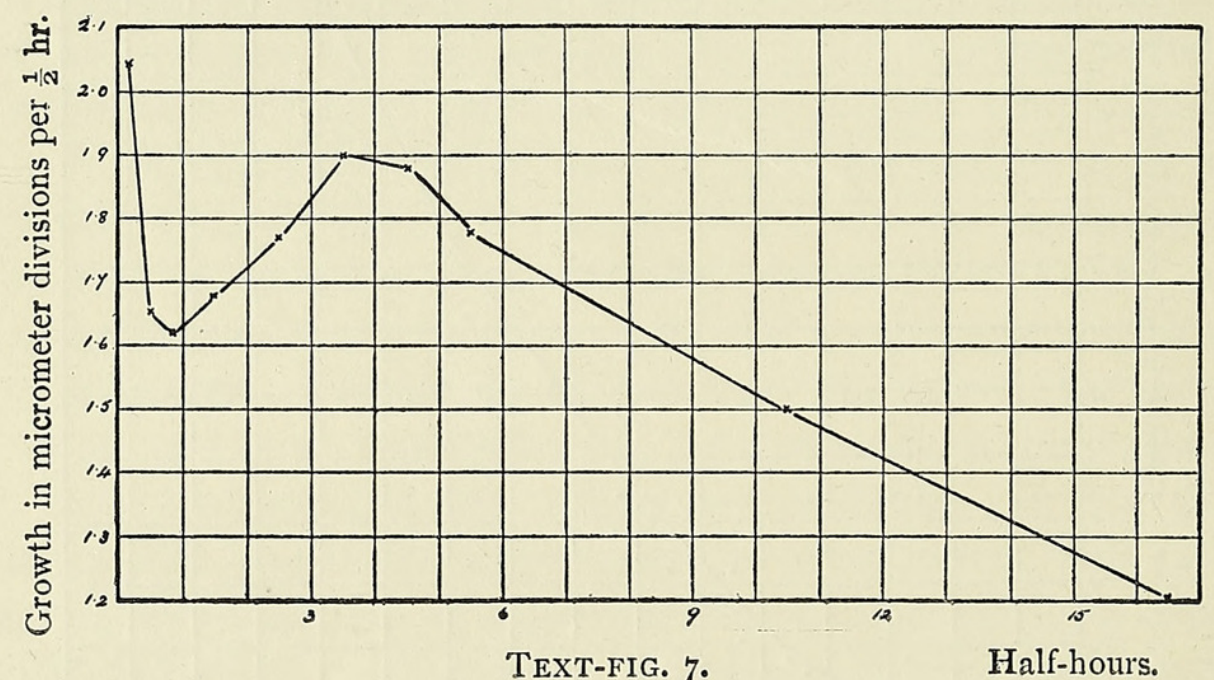

owing to the difficulty of the analysis and the necessity for many experiments, I considered it best not to experiment at random temperature intervals as before, but to restrict the experiments to a few temperatures. They are, approximately, $30^{\circ}, 35^{\circ}, 40^{\circ}, 42.5^{\circ}$, and $45^{\circ}$, and Table IV gives the results for these temperatures. The results for $30^{\circ}, 35^{\circ}$, and $40^{\circ}$ respectively are plotted in Text-figs. 7,8 , and 9.

For the experiments at $30^{\circ}$ the standard deviation and probable error have been calculated for the readings in the first ten minutes, and for those in the first half-hour. They are :

$\begin{array}{lcccc} & \text { Mean. } & \text { Standard Deviation. } & \text { Probable Error. } & \text { No. } \\ \text { First ten minutes. } & 0.68 & 0.128 & 0.033 & \text { I5 } \\ \text { First half-hour. } & \mathrm{I} \cdot 74 & 0.279 & 0.043 & 43\end{array}$

In both cases the probable error is, considering the small number of readings, satisfactorily small, and compares very well with the results in the earlier experiments, 
Temperature on the Rate of Growth in Pisum sativum. 37

The meaning of the results may be summarized thus: The rate of growth in the first ten minutes at $3.30^{\circ}$ is the highest rate obtained; in the

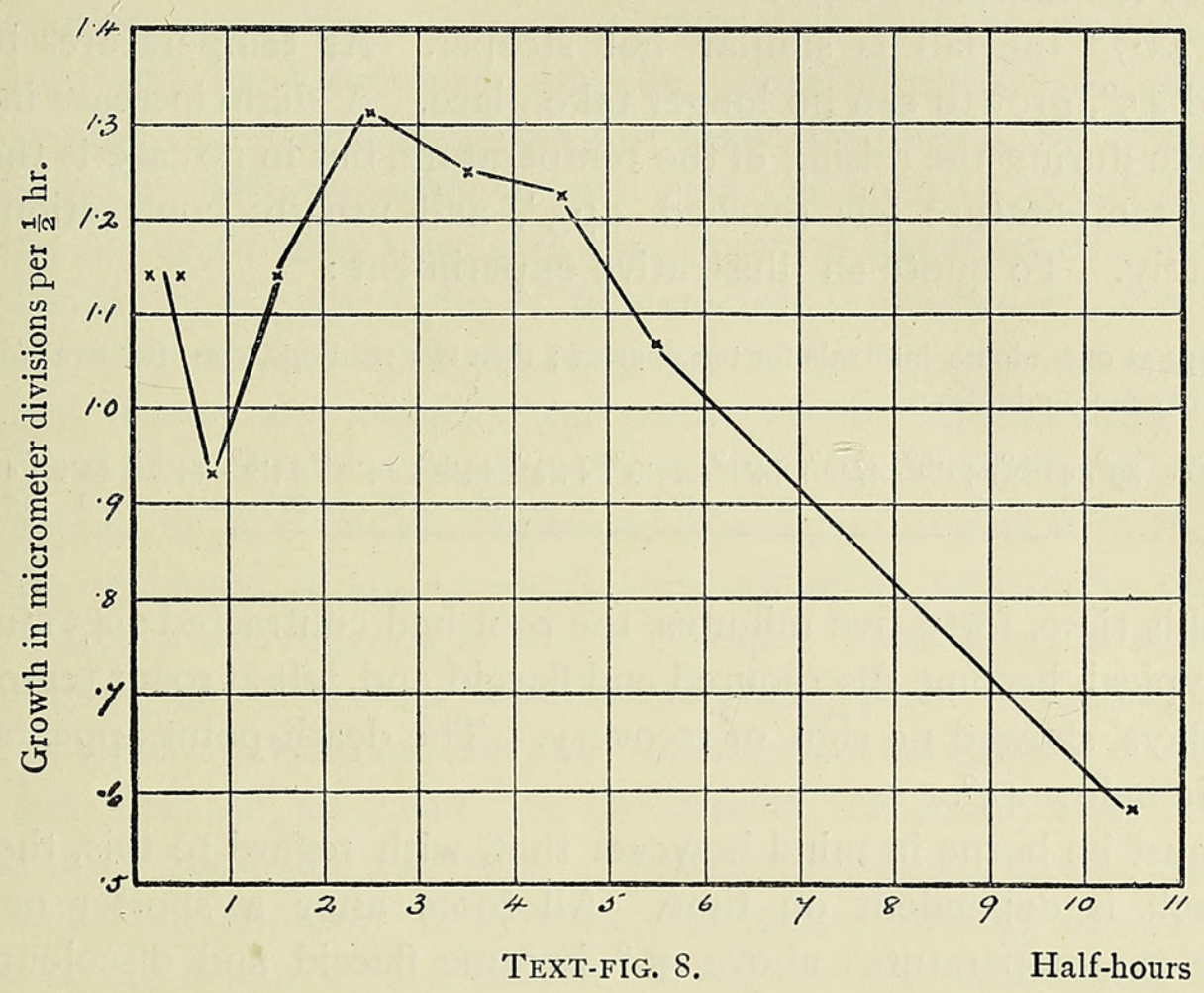

first half-hour it falls rapidly to a minimum, and thereafter a recovery takes place, giving a second maximum in the fourth half-hour. After that the rate falls uniformly and rather slowly, being about two-thirds of its initial value after eight hours.

At $35^{\circ}$ the course of events is similar, but the rise and fall are steeper. Here readings were taken in the five minutes which the temperature takes to rise from about $30^{\circ}$ to $35^{\circ}$. These gave a mean value of 0.33 in five minutes, or 0.66 in ten minutes, in contrast to 0.38 in the next ten minutes. It is to be noted that this is nearly equal to, but lower than, that in the first ten minutes at $30^{\circ}$.

At $40^{\circ}$ things are again entirely different : here the rate falls uniformly and rapidly, showing no recovery. Here also readings were taken in the five-minute

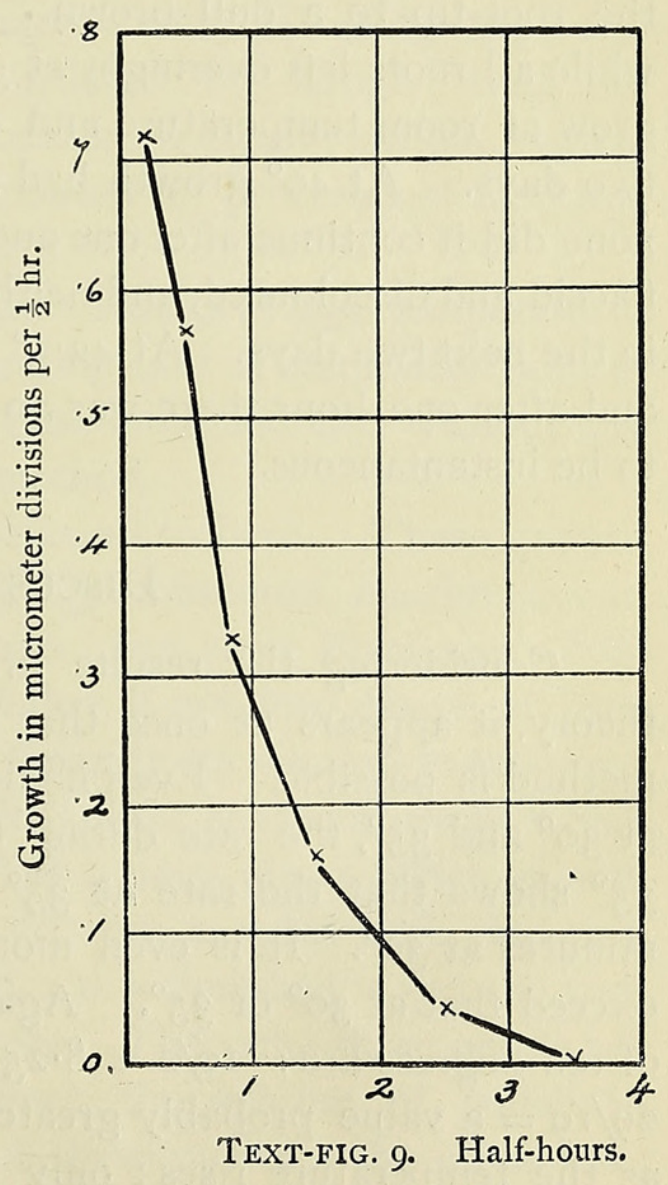


period while the temperature rises from about $33^{\circ}$ to $40^{\circ}$, and they give a value of $0.5^{\circ}$ in ten minutes, which is more than twice as high as the value in the first ten minutes at $40^{\circ}$.

At $42.7^{\circ}$ the fall is similar but steeper. At temperatures between $44.5^{\circ}$ and $45^{\circ}$, growth can no longer take place. A slight increase in length takes place during the raising of the temperature, but in no case is there any after the temperature has reached $44.5^{\circ}$, and usually contraction occurs immediately. To quote an illustrative experiment :

Readings at one-minute intervals for ten minutes; then two readings, one after five minutes and one after thirty more minutes :

Temperature. $39^{\circ}, 4^{\mathrm{I}} \cdot 8^{\circ}, 4^{2} \cdot 8^{\circ}, 43^{\circ} 8^{\circ}, 44^{\circ} 1^{\circ}, 44^{\circ} 3^{\circ}, 44^{\circ} 5^{\circ}, 44^{\circ} 8^{\circ}, 44^{\circ} 8^{\circ}, 44^{\circ} 8^{\circ}, 44^{\circ} 8^{\circ}, 44^{\circ} 9^{\circ}, 44 \cdot 9^{\circ}$ Growth.

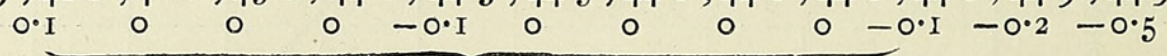

In this time, forty-five minutes, the root had contracted $0.45 \mathrm{~mm}$., had, as was typical, become discoloured and flaccid and, left at room temperature for two days, showed no sign of recovery. The death-point appears therefore to lie below $45^{\circ}$.

It must be borne in mind however that, with regard to this, the deathpoint itself is dependent on time. All roots after a shorter or longer exposure to temperatures above $30^{\circ}$ became flaccid and discoloured, the normal colour of the root changing to a dull white, and the greeny-yellow of the root-tip to a dull brown. At $35^{\circ}$ this required several hours; but, while all roots left overnight at $35^{\circ}$ were killed, the shoots recommenced to grow at room temperature and continued quite vigorously during the next two days. At $40^{\circ}$ growth had stopped in most roots after an hour, and in none did it continue after one and a half hours. In two hours the roots were flaccid and discoloured, and neither the roots nor the shoots showed recovery in the next two days. At $42.7^{\circ}$ growth occurred only in the first half-hour, and after one hour there was no recovery. At or below $45^{\circ}$, death seemed to be instantaneous.

\section{Discussion of Results.}

Considering the results first from the point of view of Blackman's theory, it appears at once that no extrapolation according to Blackman's method is possible. Even if there were not the sudden drop and recovery at $30^{\circ}$ and $35^{\circ}$, the rate during the raising of the temperature from $30^{\circ}$ to $35^{\circ}$ shows that the rate at $35^{\circ}$ never does rise above that in the first ten minutes at $30^{\circ}$. It is even more evident that the rate at $40^{\circ}$ never does exceed that at $30^{\circ}$ or $35^{\circ}$. Again, the coefficients for a rise of temperature of ten degrees are : $10 / 0=8 \cdot 25, I_{5} / 5=4 \cdot 07,20 / 10=2 \cdot 90,25 / 15=2 \cdot 38$, $29 / 19=$ a value probably greater than 2. They show a very distinct fall as the temperature rises; only between $10^{\circ}$ and $29^{\circ}$ do they lie between 
2 and 3 . The curve representing the relation of growth to temperature cannot, therefore, be regarded as a van 't Hoff curve.

Regarding this point, Puitter, basing his theory on experiments on skin-respiration in the Frog, has attempted to show that the relation between temperature and any life-process may be expressed graphically as a van't Hoff curve, and that deviations from this curve are due to the superposition of exponentials. His experiments are however open to objection on the ground that he neglects to take into consideration the effect of muscle-tone, a point shown by Krogh to be of fundamental importance. Kuijper has worked out the relation between temperature and respiration in Lupinus, Pisum, and Vicia, and regards the curve which expresses the relation as a van't Hoff. In this case, however, as in others cited by Pütter, only the coefficients of the middle region show an approximation to the proper magnitude-between 2 and 3 -and this region is arbitrarily chosen as that on which most reliance is to be placed. That there is no question of a middle region of 'correct' coefficients giving place, at the two ends, to regions in which deviations are due to extreme conditions, is indicated by the fact that, in all cases, the coefficients fall continuously from the lowest to the highest temperatures. On the other hand, Krogh insists that for 'standard metabolism' in animals, the curve relating temperature to intensity is not a van 't Hoff curve. If we plot my curve with Kuijper's for respiration in Pisum, and Krogh's for 'standard metabolism', on the same axes, we find that the three are strikingly similar (Text-fig. I0); and this fact strongly supports the view enunciated by Krogh 'that the temperature relations of physiological processes do follow certain typical curves which seem to be identical or nearly related for processes of the same fundamental nature in different organisms.'

It is interesting, also, to compare Kuijper's results at high temperatures with mine. At $30^{\circ}$ and $35^{\circ}$ he finds a fluctuating rate of respiration, and at $40^{\circ}$ and above, a uniform fall in succeeding time-intervals, also without any possibility of extrapolation by Blackman's method.

The question of terminology may be referred to here. These growth experiments at once suggest the old terminology, minimum, maximum, and optimum. But the use of the word 'optimum' has, since Blackman's ('05) paper on 'Optima and Limiting Factors', fallen, if not into disuse, at least into disrepute. Now the process of growth shows in its relation to temperature three well-marked points. $-2^{\circ} \mathrm{C}$. is the lowest temperature at which growth takes place. Between $44^{\circ}$ and $45^{\circ}$ lies a point above which growth ceases practically instantaneously. About $29^{\circ}$ lies a point such that any increase of temperature means the introduction of a time-factor and the consequent continuous decrease in the growth-rate. The same three points are distinguishable in any of the other processes the relation of which to temperature has been studied. The first of these points is the minimum; 
the second the maximum. It is suggested that the term optimum should properly be applied to the third. The reason for the confusion which exists with regard to this term is that the point is usually lower than that

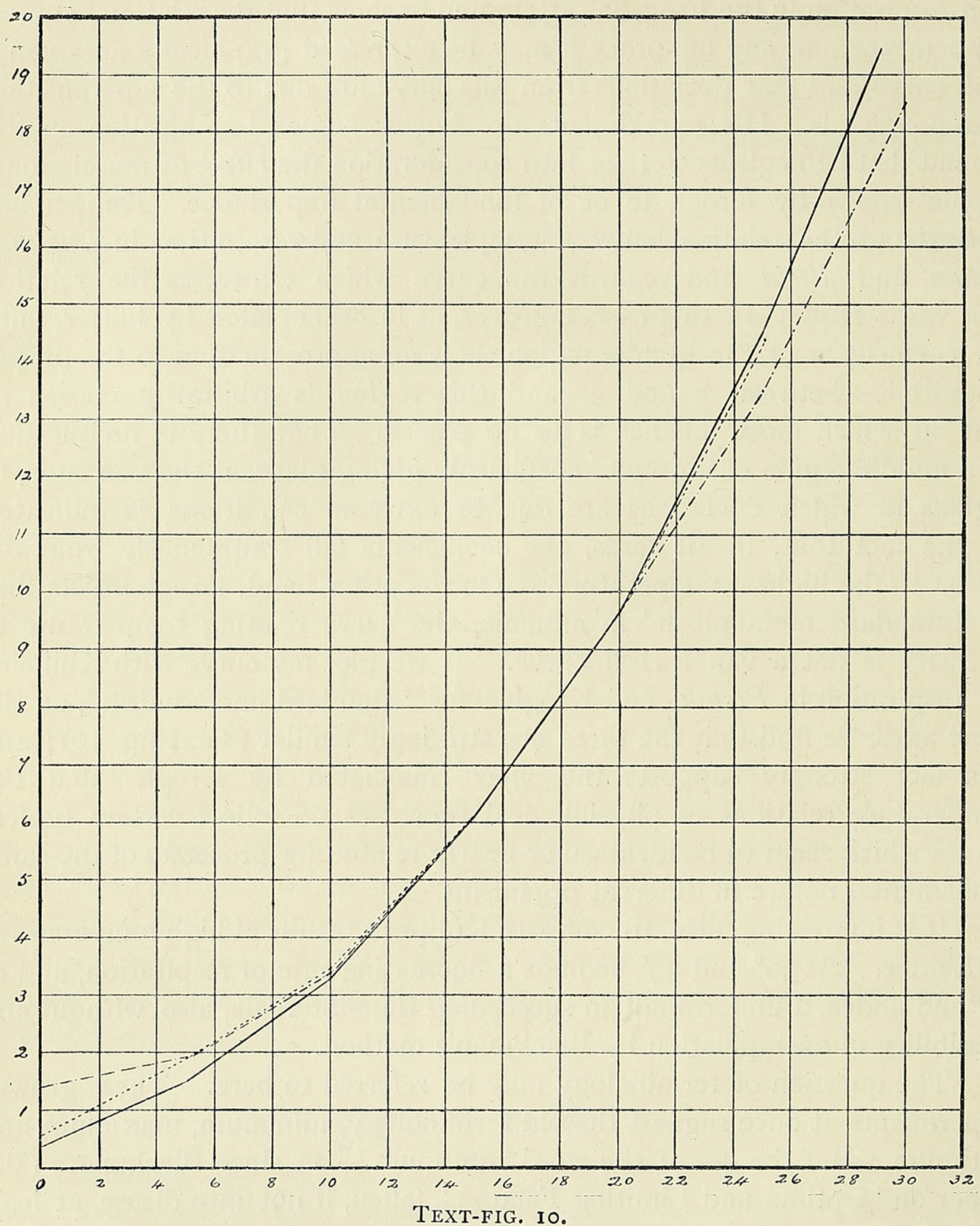

I, for growth curve, represents growth of $0 \cdot \mathrm{I}$ on Text-fig. 6 . Temperature in ${ }^{\circ} \mathrm{C}$.

I, for Krogh's curve, represents $39 \cdot 34$ on his scale.

I, for Kuijper's curve, represents $3 \cdot 03$, ",

Growth.

-........ Krogh.

on-.-.-.- Kuijper.

at which a process shows its maximum intensity, and that the idea of optimum, originally founded on long-period experiments, has been associated with apparent maximum intensity. More exact analysis has shown the 
presence of a time-factor, and a change in the conception of the meaning of the optimum has become necessary. It is absurd to apply the term, as Kuijper does, to a temperature at which the process shows a very high initial intensity and then a more or less rapid drop to an intensity below that obtained at lower temperatures. It seems logical, on the other hand, to apply it to the highest temperature at which the process takes place at a constant rate. What is important is, that this point possesses an objective reality just as do the maximum and minimum points.

If the term 'optimum' is used in this sense, it becomes necessary to distinguish another point at which the intensity of the process is at its maximum. This may be illustrated by reference to the relation of temperature to respiration in Pisum. Kuijper, by using very short experimentation-times, finds that the initial intensity of respiration is higher with rising temperature almost to the maximum temperature. Probably with infinitely short periods it would be found that at the maximum temperature the initial intensity would be the maximum intensity for a very short time. That is, the maximum-rate temperature would coincide with the maximum temperature. In the case of growth, the relation is different. The highest measured rate occurs in the first ten minutes at $30.3^{\circ}$, and it has been shown that, at higher temperatures, a higher rate does not occur even for a very short time. Between $28^{\circ}$ and $30^{\circ}$ lies the optimum point. Its exact determination experimentally is a matter of very great difficulty, if it is, in fact, at all possible. But it seems probable that, if exact analysis of this interval could be carried out, there would be found a temperature at which the rate would be equal to, or higher than, that at $30.3^{\circ}$ and at which no time-factor would be in operation. This would be the optimum, and, in this case, the maximum-rate temperature would ultimately coincide with the optimum. The probable coincidence, in the limiting case of the maximum-rate temperature, with the optimum or the maximum cannot be demonstrated, on the one hand, because of the curvatures which take place, and on the other, because it is impossible to experiment with infinitely short periods. Therefore the maximum-rate temperature remains, at least experimentally, distinct.

It would seem, then, that four cardinal points are to be distinguished for all investigated physiological processes :

The minimum temperature for any process is the lowest temperature at which the process takes place.

The maximum temperature is the highest temperature at which the process takes place.

The optimum temperature is the highest temperature at which there is no time-factor operating, and

The maximum-rate temperature is that temperature at which the process attains to its highest intensity. 
With regard to a possible explanation of the second maxima shown in the time-growth curves, at $30^{\circ}$ and $35^{\circ}$, reference may be made to a recent paper of Miss Sophia Eckerson ('14) on Thermotropism in Roots. The author shows that changes in the thermotropic reaction are due to changes in the permeability of the roots at certain critical temperatures. In the case of Pisum, a decrease in permeability takes place between $30^{\circ}$ and $40^{\circ}$, resulting in a negative curvature in roots exposed to a higher temperature on one side, in that range. It is possible that roots exposed to temperatures within that range might show a secondary elongation due to osmotic phenomena, which, superimposed on a simple time-growth curve, would give rise to a temporary second maximum. Too much stress should not, however, be laid on this coincidence. As already stated, Kuijper's respiration determinations also show fluctuations at temperatures between $30^{\circ}$ and $40^{\circ}$, and it is possible that both these and the second maximum in growth may be due to deeper, unanalysed metabolic processes.

\section{SUMMARY.}

The relation of growth to temperature can be expressed as a uniform curve from $-2^{\circ}$ to about $29^{\circ}$. It is not a van 't Hoff curve, but shows a very close resemblance to the curves found by Krogh for 'standard metabolism in animals', and by Kuijper for respiration in Pisum.

Above $29^{\circ}$ the relation can no longer be expressed as a curve, but for each higher temperature a different curve must be constructed to express the rate of growth in successive time-intervals. Between $30^{\circ}$ and $40^{\circ}$ these curves are not simple time-curves, and no extrapolation is possible.

For growth there is a well-marked optimum temperature. The general applicability of this term to physiological processes is considered, and a definition offered. A further point, the maximum-rate temperature is distinguished and defined.

For growth, the minimum temperature is $-2^{\circ}$; the maximum $44.5^{\circ}$; to the degree of accuracy found possible the optimum temperature is between $28^{\circ}$ and $30^{\circ}$, and the maximum-rate temperature is $30.3^{\circ}$.

This work was carried out in the University Plant-physiology Laboratory in Copenhagen during my tenure of a Carnegie Research Scholarship. I have to express my indebtedness to Professor Johannsen for the suggestion to perform these experiments, and for the opportunity to do so; and to Dr. Boysen-Jensen for many helpful suggestions, for his continued interest in the work, and for much of that sceptical criticism which keeps one in the strict path of verification. 


\section{TABLE I.}

In each experiment thirty-five peas were used; the figures for initial length and growth are means. The columns give, in order, initial length, growth in $\mathrm{mm}$. in $22 \frac{\mathrm{I}}{2}$ hours, temperature, standard deviation, and probable error of the mean.

The experiments are in chronological order.

Series I.

Initial Length. Growth.

$\begin{array}{rr}I 8 \cdot 9 I & 8 \cdot 56 \\ 2 I \cdot 23 & I 4 \cdot I 8 \\ 22 \cdot 79 & I 7 \cdot 3^{2} \\ 2 I \cdot 74 & 17 \cdot 09 \\ 2 I \cdot I 8 & 17 \cdot 32 \\ I 4 \cdot I 7 & 2 I \cdot 00 \\ I 4 \cdot 74 & 22 \cdot 33 \\ I 6 \cdot 96 & 22 \cdot 00 \\ 2 I \cdot I 3 & 25 \cdot 33 \\ 20 \cdot 80 & 25 \cdot 45 \\ I 9.68 & 30 \cdot 00 \\ I 5.97 & 28 \cdot 60 \\ I 4.65 & 25 \cdot 35\end{array}$

Series 2.

\begin{tabular}{|c|c|}
\hline $\begin{array}{l}16 \cdot 27 \\
15 \cdot 82\end{array}$ & $\begin{array}{l}5 \cdot 89 \\
6 \cdot 62\end{array}$ \\
\hline I $8 \cdot 94$ & I 4.44 \\
\hline I9.53 & I9. 17 \\
\hline $19 \cdot 38$ & I 8.03 \\
\hline 19.96 & 19.00 \\
\hline $2 I \cdot 6_{5}$ & 19.76 \\
\hline $18 \cdot 44$ & $2 I \cdot I 8$ \\
\hline $17 \cdot 7^{2}$ & $21 \cdot 93$ \\
\hline $18 \cdot 40$ & $2 \mathrm{I} \cdot 37$ \\
\hline I $3 \cdot 63$ & $22 \cdot 90$ \\
\hline II $\cdot 24$ & $25 \cdot I 8$ \\
\hline 10.47 & $26 \cdot 29$ \\
\hline I 2.53 & $25^{\circ} \mathrm{O} 2$ \\
\hline $14 \cdot 65$ & $25 \cdot 94$ \\
\hline $15{ }^{\circ} 7 \mathrm{I}$ & $27 \cdot 68$ \\
\hline $14^{\circ} 5^{6}$ & $27 \cdot 86$ \\
\hline $12 \cdot 24$ & $28 \cdot 97$ \\
\hline 10.85 & $32 \cdot 76$ \\
\hline $9 \cdot 26$ & $29 \cdot 46$ \\
\hline 20.75 & 26.08 \\
\hline I9.50 & $24 \cdot 28$ \\
\hline 16.5 & $23^{\circ} 5^{6}$ \\
\hline $10 \cdot 76$ & $27 \cdot 64$ \\
\hline I 5.57 & $I \cdot 40$ \\
\hline 9.77 & 0.82 \\
\hline 10.87 & $28 \cdot I 8$ \\
\hline $9^{\circ} \mathrm{I} 5$ & 0.68 \\
\hline
\end{tabular}

Series 3.
Temperature. Standard Deviation. Probable Error.
$I \cdot 7354$
$2 \cdot 4428$
$2 \cdot 79$ I I
$3 \cdot 95$ I I
$3 \cdot 0308$
$2 \cdot 9186$
$2 \cdot 8922$
$3 \cdot 8829$
$3 \cdot 8588$
$4 \cdot 0797$
$5 \cdot 3742$
$5 \cdot 55^{1} 9$
$4 \cdot 9254$

$I \cdot 2598$

$I^{\bullet} 2 \mathrm{I} 33$

$\mathrm{I} \cdot 8 \mathrm{I} 79$

$\mathrm{I} \cdot 6302$

$2 \cdot 3288$

$2 \cdot 507 \mathrm{I}$

$3 \cdot 2568$

$2 \cdot 3695$

$2 \cdot 1763$

3.5955

$3 \cdot 6534$

$2 \cdot 9566$

$3 \cdot 2970$

$2 \cdot 8$ I 13

$3 \cdot 1660$

$2 \cdot 906$ I

3.21 95

$3 \cdot 2897$

$2 \cdot 7343$

I.64I 6

$3 \cdot 9176$

4.498 I

3.2528

2. I 393

0.8000

0.3856

2.7500

0.4583

0.9545

I.0993

0.4679

I.I 709

I. 8377

I.37I

I.I097

I. 2338

I. 3896

I. 4783

I.8935
0.2976
$0.4^{2} 5^{2}$
0.5275
0.6776
0.5443
0.5727
0.5047
0.7615
0.7045
0.7102
0.9217
0.9521
0.8447

0.2129

0.208 I

0.3 II 8

0.2756

0.4054

0.4238

0.5669

0.4064

$0.4 \mathrm{I} 88$

$0.6_{5} 6_{4}$

0.7618

$0.499^{8}$

0.6019

$0.475^{2}$

$0.533^{8}$

0.5059

0.552 I

$0.556 \mathrm{I}$

0.5362

$0.398 \mathrm{I}$

0.8760

I 3562

$0 \circ 5939$

0.3842

0.2066

O.I 162

0.6875

0.1025

0.1662

०. $185^{8}$

0.0802

0.2008

0.3106

0.2319

0.1903

0.2148

$0.25^{80}$

0.2535

$0.324^{2}$ 


\section{TABLE I (continued).}

Initial Length.

Growth.

Temperature. Standard Deviation. Probable Error.

\begin{tabular}{|c|c|}
\hline 14.33 & I3.6I \\
\hline 14.89 & 12.65 \\
\hline I $3.2 I$ & $16 \cdot 27$ \\
\hline $16 \cdot 15$ & 18.84 \\
\hline 23.63 & 18.13 \\
\hline $20 \cdot 43$ & 22.49 \\
\hline $20 \cdot 54$ & 22.96 \\
\hline I 5.97 & $27 \cdot 20$ \\
\hline 14.97 & $28 \cdot 26$ \\
\hline 13.16 & $29 \cdot 89$ \\
\hline I3.79 & $28 \cdot 37$ \\
\hline I 2.53 & $\begin{array}{c}26 \cdot 93 \\
0 \cdot 0\end{array}$ \\
\hline 14.35 & $0 \cdot 5^{6}$ \\
\hline I $4 \cdot 39$ & $2 \cdot 38$ \\
\hline 12.53 & $3 \cdot 36$ \\
\hline 14.47 & $3 \cdot 87$ \\
\hline 13.44 & $2 \cdot 31$ \\
\hline
\end{tabular}

$$
\begin{aligned}
& \text { I } 4 . \mathrm{I}^{\circ} \\
& \begin{array}{l}
14.4^{\circ} \\
16.3^{\circ}
\end{array} \\
& \begin{array}{l}
16.3^{\circ} \\
19.9^{\circ}
\end{array} \\
& 20.3^{\circ} \\
& 22 \cdot 2^{\circ} \\
& 24.7^{\circ} \\
& 27.0^{\circ} \\
& 27.7^{\circ} \\
& 30 \cdot 3^{\circ} \\
& 33^{\circ} \cdot 8^{\circ} \\
& \begin{array}{r}
-3.5^{\circ} \\
-0.5^{\circ}
\end{array} \\
& \begin{array}{r}
-0.5^{\circ} \\
2.8^{\circ}
\end{array} \\
& 4.0^{\circ} \\
& \begin{array}{l}
4 \cdot 5^{\circ} \\
\mathrm{I} \cdot 5^{\circ}
\end{array}
\end{aligned}
$$

I. 5340
$2 \cdot 3581$
$2 \cdot 4438$
$2 \cdot 2701$
3.8966
$2 \cdot 2871$
3.7125
$3.535^{8}$
$5 \cdot 0273$
$2 \cdot 5092$
4.7522
$4 \cdot 2702$
0.2449
0.8400
0.6001
$I \cdot 0738$
0.7079

0.2849

0.4105

0.4389

$0.445^{2}$

$\mathrm{I} \cdot 006 \mathrm{I}$

0.4402

0.7145

0.6064

0.8622

0.4436

0.8150

0.7548

0.0837

0.1420

$0 \cdot 1029$

$0 \cdot 1869$

$0 \cdot 1197$

\section{TABLE II.}

\section{Grand Period Experiments.}

The columns give in order (I) the number of the experiment; (2) the number of days of growth before the change of temperature from thermostat temperature; (3) the temperature of the experiment; (4) the day on which the Grand Period occurs ; (5) the growth in $\mathrm{mm}$. on that day; (6) the day on which the side-roots appear; (7) the length of the main root, in mm., at the end of that day; (8) the number of peas measured in each experiment:

\begin{tabular}{lllll} 
I & 2 & \multicolumn{1}{c}{3} & 4 & 5 \\
I. & 2 & $10^{\circ}-12^{\circ}$ & 3 & $13 \cdot 7$ \\
2. & - & $15^{\circ}-17^{\circ}$ & $3-4$ & $14 \cdot 5$ \\
3. & 2 & $16^{\circ}$ & 3 & 18 \\
4. & 2 & $25^{\circ}$ & 3 & 33 \\
5. & 2 & $25^{\circ}$ & 3 & 27 \\
6. & 1 & $26 \cdot 3^{\circ}$ & 2 & $3^{\circ}$ \\
7. & 2 & $26.5^{\circ}$ & 3 & 35 \\
8. & 2 & $26.8^{\circ}$ & 3 & $3^{8}$
\end{tabular}

$\begin{array}{ccc}6 & 7 & 8 \\ \text { IO } & 84 \cdot 5 & 3 \\ \text { IO } & 8 \mathrm{I} & 2 \\ 6 & 85 & \text { I } \\ 4 & 87 & \text { I } \\ 4 & 7 \mathrm{I} & \text { I } \\ 3 & 8 \mathrm{I} & \text { I } \\ 4 & 83 & \text { I } \\ 4 & 87 & \text { I }\end{array}$

Conditions uniform from beginning:

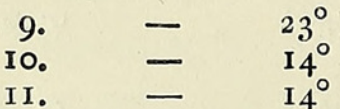
$3^{I} \cdot \stackrel{5}{I}$
4
7
7 and 8
$\begin{array}{ll}85 & 6 \\ 87 & 5 \\ 89 & 5\end{array}$

In Experiment 2 there is no change of temperature; it is at thermostat temperature throughout. 


\section{TABLE III.}

The columns give respectively (I) the number of roots measured in each case; (2) the temperature for each experiment; (3) the mean rate of growth per half-hour in micrometer divisions; (4) the rate calculated in millimetres per $22 \frac{1}{2}$ hours; and (5) figures from Text-fig. 3 for comparison.

\begin{tabular}{|c|c|c|c|c|}
\hline No. & Temperature. & $\begin{array}{l}\text { Mean rate per } \\
\frac{1}{2} \text { hour in micro- } \\
\text { meter divisions. }\end{array}$ & $\begin{array}{l}\text { Mean rate } \\
\text { per } 22 \frac{1}{2} \text { hours } \\
\text { in } \mathrm{mm} \text {. }\end{array}$ & Text-fig \\
\hline I & $0.8^{\circ}$ & 0.06 & I. 59 & $I \cdot 3$ \\
\hline I & $I \cdot 0^{\circ}$ & 0.05 & $I \cdot 26$ & $\mathrm{I} \cdot 4$ \\
\hline I & $3 \cdot 7^{\circ}$ & O.I I & $2 \cdot 77$ & $2 \cdot 8$ \\
\hline 2 & $4.7^{\circ}$ & 0.18 & 4.48 & 3.5 \\
\hline 3 & $4.9^{\circ}$ & O.I 3 & $3 \cdot 28$ & $3 \cdot 6$ \\
\hline I & $5 \cdot 5^{\circ}$ & 0.27 & 6.88 & $4 \cdot I$ \\
\hline 2 & $6.0^{\circ}$ & 0.25 & $6 \cdot 30$ & 4.4 \\
\hline 2 & $6.0^{\circ}$ & $0.2 \mathrm{I}$ & $5 \cdot 3 \circ$ & \\
\hline 2 & $8 \cdot 6^{\circ}$ & 0.26 & 6.50 & $\begin{array}{l}7.9 \\
6.8\end{array}$ \\
\hline 3 & $9^{\circ} 1^{\circ}$ & 0.27 & $6 \cdot 93$ & $7 \cdot 3$ \\
\hline 3 & $9 \cdot 9^{\circ}$ & 0.37 & $9 \cdot 45$ & $8 \cdot 2$ \\
\hline 3 & $10.6^{\circ}$ & $0.3 \mathrm{I}$ & $7 \cdot 76$ & $9 \cdot 0$ \\
\hline 3 & II $1 \cdot 0^{\circ}$ & 0.42 & 10.6 & $9 \cdot 3$ \\
\hline 2 & I I $\cdot 9^{\circ}$ & $0.4 \mathrm{I}$ & $10 \cdot 3$ & $10 \cdot 3$ \\
\hline 2 & I $2 \cdot 2^{\circ}$ & 0.46 & II $\cdot \%$ & 10.7 \\
\hline 2 & I $3.5^{\circ}$ & 0.50 & 12.6 & I $2 . \mathrm{I}$ \\
\hline 3 & $14.5^{\circ}$ & 0.67 & I6.8 & I $3 \cdot 2$ \\
\hline 3 & $14.5^{\circ}$ & 0.54 & 13.6 & $13^{\circ 2}$ \\
\hline 3 & $14.75^{\circ}$ & 0.49 & I $2 \cdot 25$ & I 3.5 \\
\hline 3 & $18.3^{\circ}$ & $0.9 \mathrm{I}$ & $22 \cdot 8^{\circ}$ & $173^{\circ}$ \\
\hline 4 & $194^{\circ}$ & 0.82 & 20.7 & 18.5 \\
\hline 3 & $21 \cdot 8^{\circ}$ & $I \cdot I O$ & 27.7 & $2 \mathrm{I} \cdot \mathrm{I}$ \\
\hline 4 & $23.0^{\circ}$ & $I \cdot 20$ & $30 \cdot 2$ & $22 \cdot 4$ \\
\hline 3 & $23.0^{\circ}$ & $I \cdot 3 I$ & 33.0 & $22 \cdot 4$ \\
\hline 4 & $239^{\circ}$ & $I \cdot 50$ & $37 \cdot 8$ & $23 \cdot 3$ \\
\hline 3 & $25^{\circ} 0^{\circ}$ & $I \cdot 40$ & $35^{\circ} 3$ & 24.5 \\
\hline 4 & $26 \cdot I^{\circ}$ & I. 60 & $40 \cdot 8$ & 25.8 \\
\hline 3 & $26 \cdot 3^{\circ}$ & $I \cdot 60$ & $40 \cdot 8$ & $26 \cdot 0$ \\
\hline 3 & $26 \cdot 5^{\circ}$ & $I \cdot 70$ & $4^{2} \cdot 6$ & \\
\hline & $26.6^{\circ}$ & $\mathrm{I} \cdot 80$ & 45.4 & $26 \cdot 4$ \\
\hline 6 & $26 \cdot 7^{\circ}$ & $I \cdot 60$ & 40.8 & $26 \cdot 5$ \\
\hline I & $27 \cdot 6^{\circ}$ & $I \cdot 60$ & $40 \cdot 8$ & $270^{\circ}$ \\
\hline I & $27 \cdot 7^{\circ}$ & $I \cdot 65$ & $4 \mathrm{I} \cdot 6$ & $27 \cdot 5$ \\
\hline 7 & $29^{\circ} 3^{\circ}$ & $I \cdot 90$ & $48 \cdot 6$ & $29 \cdot 3$ \\
\hline
\end{tabular}

\section{TABLE IV.}

\section{Relation of Growth to Time at High Temperatures.}

The first column gives temperature; the second, third, and fourth, the growth in the first three ten-minute intervals; the fifth column to the tenth give the growth in the first six half-hour intervals ; in the eleventh is given the growth in the eleventh half-hour; and in the twelfth, that in the seventeenth half-hour. The numbers in brackets indicate the number of peas measured in each case.

Temp. Ten-minute Intervals.

Half-hour Intervals.

\begin{tabular}{|c|c|c|c|c|c|c|c|c|c|c|}
\hline I & 2 & 3 & 4 & 5 & 6 & 7 & 8 & 9 & IO & II \\
\hline $30.3^{\circ}$ & $\begin{array}{l}0.68 \\
\left(I_{5}\right)\end{array}$ & 0.55 & 0.54 & $\begin{array}{l}I \cdot 74 \\
(43)\end{array}$ & $\begin{array}{l}\mathrm{I} \cdot 68 \\
(32)\end{array}$ & $\begin{array}{l}1 \cdot 77 \\
(20)\end{array}$ & $\begin{array}{l}I \cdot 90 \\
(\mathrm{I} 2)\end{array}$ & $\begin{array}{l}\mathrm{I} \cdot 88 \\
(\mathrm{I} I)\end{array}$ & $\begin{array}{l}I \cdot 78 \\
(\mathrm{IO})\end{array}$ & $\begin{array}{l}\mathrm{I} \cdot 5 \\
(3)\end{array}$ \\
\hline $35^{\circ} 0^{\circ}$ & $\begin{array}{l}0.38 \\
\text { (I } 3)\end{array}$ & $0.3^{8}$ & $0.3^{I}$ & $\begin{array}{l}\text { I.09 } \\
\text { (I } 5)\end{array}$ & $\begin{array}{l}\text { I. I } 4 \\
(8)\end{array}$ & $\begin{array}{l}I \cdot 3 I \\
(8)\end{array}$ & $\begin{array}{l}\mathrm{I} \cdot 25 \\
\text { (II) }\end{array}$ & $\begin{array}{l}\mathrm{I} \cdot 23 \\
(\mathrm{IO})\end{array}$ & $\begin{array}{l}\mathrm{I} \cdot 07 \\
(9)\end{array}$ & $\begin{array}{l}0.5^{8} \\
(9)\end{array}$ \\
\hline $40 \cdot 5^{\circ}$ & $\begin{array}{l}0 \cdot 3) \\
0.24 \\
(8)\end{array}$ & 0.19 & $0.1 \mathrm{I}$ & $\begin{array}{l}0.54 \\
(8)\end{array}$ & $0 \cdot 16$ & 0.04 & 0.0 & & & \\
\hline $4^{2} \cdot 7^{\circ}$ & $\begin{array}{l}0.12 \\
(6)\end{array}$ & 0.03 & 0.02 & 0.17 & 0.0 & & & & & \\
\hline $44^{\circ} 5^{\circ}$ & 0.0 & & & & & & & & & \\
\hline
\end{tabular}




\section{LITERATURE CITED.}

Askenasy: Ueber einige Beziehungen zwischen Wachstum und Temperatur. Ber. d. d. Bot. Gesellsch., Bd. viii, I890, p. 6 r.

Blackman : Optima and Limiting Factors. Ann. of Bot., vol. xix, 1905, p. 28I.

ECKERSON : Thermotropism of Roots. Bot. Gaz., vol. lviii, I9I 4, p. 254.

Jost : Vorlesungen über Pflanzenphysiologie. 3. Aufl., I9I3, p. 40 I.

KanitZ: Der Einfluss der Temperatur auf die pulsierenden Vacuolen der Infusorien und die Abhängigkeit biologischer Vorgänge von der Temperatur iiberhaupt. Biolog. Centralbl., Bd. xxvii, I907, p. II.

Köppen: Wärme und Pflanzenwachstum. Bull. de la Soc. Imp. des Naturalistes de Moscou, t. xliii, 2, I87o, p. 4I.

KROGH : The Quantitative Relation between Temperature and Standard Metabolism in Animals. Internat. Zeitschrift für physik.-chem. Biologie, Bd. i, I9I4, p. 49I.

Kuijper : Ueber den Einfluss der Temperatur auf die Atmung der höheren Pflanzen. Rec. d. Trav. bot. néerlandais, t. vii, I910, p. I 30 .

Pedersen : Haben Temperaturschwankungen als solche einen ungünstigen Einfluss auf das Wachstum? Arb. d. Bot. Inst. in Würzburg, Bd. i, I874, p. $5^{6} 3$.

Pfeffer : Pflanzenphysiologie. II, I904, p. 87.

PÜTTER: Temperaturkoefficienten. Zeitschr, f. allgem. Physiol., Bd. xvi, I9I4, p. 574.

SACHS : Physiologische Untersuchungen über die Abhängigkeit der Keimung von der Temperatur. Ges. Abh. über Pflanzenphysiologie, Bd. i, I86o, p. $5^{6}$.

Abhängigkeit der Streckungsgeschwindigkeit von inneren und äusseren Ursachen. Vorles. iiber Pflanzenphysiologie, I887, p. 55 I.

Schmidt: Humlestænglens Længdevækst og dennes daglige Periode. Medd. fra Carlsberg Lab. København, vol. x, I9I3, p. 2 II.

TRUE : On the Influence of Sudden Changes of Turgor and of Temperature on Roots. Ann. of Bot., vol. ix, 1895, p. 365 .

Vogt : Ueber den Einfluss des Lichts auf das Wachstum der Koleoptile von Avena sativa. Zeitschr. f. Bot., Bd. vii, I9I5, p. 193.

Since this paper has been in course of publication a report has appeared in Botanisches Centralblatt (I9I 5, No. 5I, p. 662) of a paper by P. A. Lehenbauer [Physiol. Res. I, I9I4, pp. 247-288] on Growth of Maize Seedlings in relation to Temperature. The paper, however, I have not been able to procure.

For Descriptions of the figures on Plate I, illustrating Miss Leitch's paper, see pp. 27 and 29. 
Annals of Botany,

N
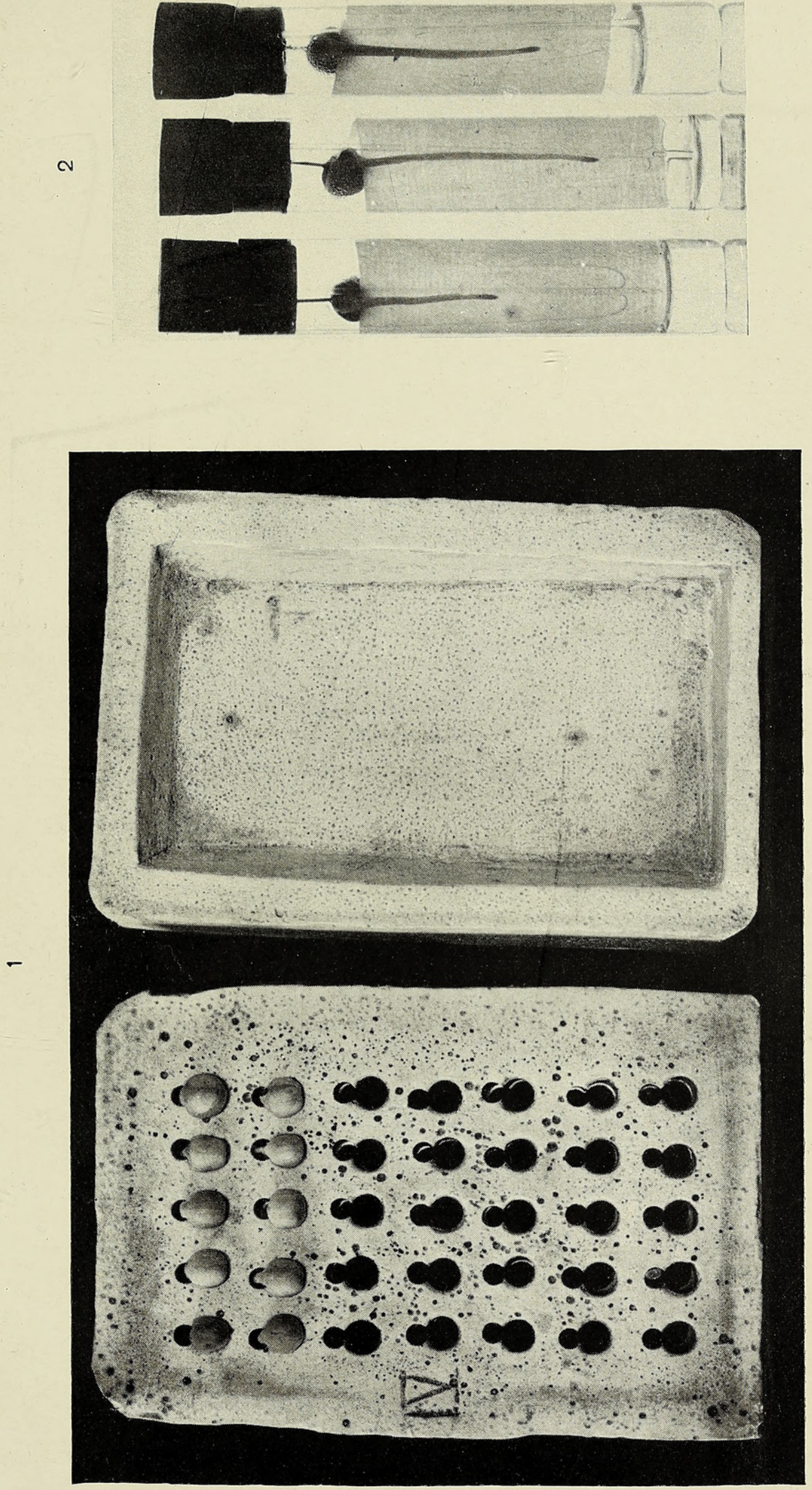


\section{$2 \mathrm{BHL}$ Biodiversity Heritage Library}

Leitch, I. 1916. "Some experiments on the influence of temperature on the rate of growth in Pisum sativum." Annals of botany 30, 25-46. https://doi.org/10.1093/oxfordjournals.aob.a089587.

View This Item Online: https://www.biodiversitylibrary.org/item/237452

DOI: https://doi.org/10.1093/oxfordjournals.aob.a089587

Permalink: https://www.biodiversitylibrary.org/partpdf/320094

\section{Holding Institution}

Smithsonian Libraries

\section{Sponsored by}

Biodiversity Heritage Library

\section{Copyright \& Reuse}

Copyright Status: Not in copyright. The BHL knows of no copyright restrictions on this item.

This document was created from content at the Biodiversity Heritage Library, the world's largest open access digital library for biodiversity literature and archives. Visit BHL at https://www.biodiversitylibrary.org. 